“C 2002 IEEE. Personal use of this material is permitted. Permission from IEEE must be obtained for all other uses, in any current or future media, including reprinting/republishing this material for advertising or promotional purposes, creating new collective works, for resale or redistribution to servers or lists, or reuse of any copyrighted component of this work in other works." 


\title{
Comparative Study of 3D Flux Electrical Machines with Soft Magnetic Composite Cores
}

\author{
Y.G. Guo ${ }^{(1)}$, J.G Zhu ${ }^{(1)}$, P.A. Watterson ${ }^{(1)}$ and W. Wu ${ }^{(2)}$ \\ ${ }^{(1)}$ Faculty of Engineering, University of Technology, Sydney \\ (2) CSIRO TIP \\ P.O. Box 123, Broadway, NSW 2007, Australia \\ P.O. Box 218, Lindfield, NSW 2070, Australia
}

\begin{abstract}
This paper compares two types of threedimensional (3D) flux electrical machines with soft magnetic composite (SMC) cores, namely claw pole and transverse flux machines. 3D electromagnetic field analysis is conducted for the computation of some important parameters and optimization of the machine structures. An Equivalent electric circuit is derived to calculate the machine performances. The analysis methods are validated by experimental results of a single phase claw pole permanent magnet machine with a SMC core. Useful conclusions are drawn from the evaluation and comparison of two machines with soft magnetic composite cores.
\end{abstract}

\section{INTRODUCTION}

Soft magnetic composite materials by powder metallurgy techniques possess a number of advantages over traditional laminated steels commonly used in electromagnetic devices and have undergone a significant development recently [1]. The basic raw material for the manufacturing of soft magnetic powder composites is iron powder of high purity and compressibility. Sometimes, alloy powders such as Fe-Ni, Fe$\mathrm{Si}, \mathrm{Fe}_{3} \mathrm{P}$, and $\mathrm{Fe}-\mathrm{Si}-\mathrm{Al}$, which are of importance as admixtures or for special application of these composites, can be used. This type of materials is in general magnetically isotropic due to its powdered nature and hence is suitable for construction of electrical machines of 3D magnetic fluxes and complex structures. This isotropic magnetic property opens up crucial design benefits and freedom that magnetic circuits can be designed with 3D flux paths.

Since the iron particles are insulated by the surface coating and adhesive used for composite bonding, the eddy current loss is much lower than that in laminated steels, especially at higher frequencies, and the hysteresis loss becomes the dominant component of core losses in soft magnetic composites. This property may allow machines to operate at higher frequencies, resulting in reduced machine size and weight.

By powder metallurgy techniques, the iron cores and parts are formed in a die, or isostatic press process, and can be combined with parts of other materials to form complex netshape components. Dimensional changes are minimized and hence the manufacturing costs are greatly reduced.
Thus, SMC materials possess great potential for application in electrical machines and may even cause a revolution of electrical machine design and manufacturing. Some researchers, such as those in the University of Newcastle upon Tyne, UK, have been working in this field for a few years and the results appear to be promising [2,3].

Unfortunately, the SMC materials have some outstanding disadvantages as well: (1) low magnetic permeability because the material has less than full density (maximum relative permeability about 500), (2) high hysteresis loss resulting from strain and poor domain structure, (3) low mechanical strength especially when high powder density is sought.

Due to these drawbacks, it is obvious that simply replacing the existing laminated iron core with a SMC core will result in a loss of performance with very small compensating benefits. To fully take the advantages of the SMC material and overcome its disadvantages, a great amount of research work is required on a better understanding of the material properties, novel motor topologies combined with appropriate production techniques, advanced field analysis and design optimization, and suitable drive techniques.

SMC materials are especially suitable for construction of 3D flux machines, for which it is almost impossible or very difficult to use laminated steels. Because the permeability of SMC materials is lower than that of electrical steels, it is expected that SMC would be most appropriate for PM machines for which the magnetic reluctance of the magnet dominates the magnetic circuit, making such motors insensitive to the permeability of the core.

This paper presents an investigation on two 3D-flux permanent magnet (PM) machines with SMC cores, namely a claw pole and a transverse flux machine. Both are designed for a core of SOMALOY ${ }^{\mathrm{TM}} 500$, a new soft magnetic composite for injection molding produced by Höganäs AB, Sweden, as the core material. The B-H characteristics and rotational core losses of SOMALOY 500 with rotating magnetic fluxes at different frequencies were measured using a single sheet rotational core loss tester developed at the University of 
Technology, Sydney (UTS) [4,5]. This material has a saturation flux density of $2.37 \mathrm{~T}$ at $340 \mathrm{kA} / \mathrm{m}$, maximum relative permeability of 500, specific alternating core loss of $10 \mathrm{~W} / \mathrm{kg}$ at $1 \mathrm{~T}$ and $50 \mathrm{~Hz}$, which is similar to $9 \mathrm{~W} / \mathrm{kg}$ of LyCore 800 silicon steel of 0.65 mm thickness produced by BHP, Australia, at $1 \mathrm{~T}$ and $50 \mathrm{~Hz}$, and specific rotational core losses of $11.15 \mathrm{~W} / \mathrm{kg}$ with a circular rotating flux density in a square sample of $1.25 \mathrm{~mm}$ thickness at $1 \mathrm{~T}$ and $50 \mathrm{~Hz}$, and $33.4 \mathrm{~W} / \mathrm{kg}$ at $1.6 \mathrm{~T}$ and $50 \mathrm{~Hz}$.

3D finite element method is used to analyze the electromagnetic field distribution in the machines. Key motor parameters are then determined and the equivalent electric circuit approach is used to evaluate the performances. The design results with different machine structures are analyzed and compared with each other. Meaningful conclusions about the application of SMC materials in electrical machines are drawn.

\section{Claw Pole Machine}

\section{A. Structure and Dimensions}

Electrical machines with electrically excited claw pole DC fields have been manufactured in mass production for many years, especially for car alternators. Their main attraction is the low cost of winding the single excitation coil within the claw pole halves. They are capable of producing power densities up to three times greater than conventional machines because the topology allows the pole number to be increased without reducing the magnetomotive force per pole.

The use of the same low cost coil and solid steel claws as the stator of a brushless DC machine with permanent magnet excited rotor is limited to very small sizes and/or low speeds due to excessive eddy currents.

Because of the complex structure, it is very difficult to construct the claw poles using electrical steel laminations. Soft magnetic composite materials offer an opportunity to overcome this problem $[2,3,6]$. To verify the idea, a small three-phase claw pole permanent magnet motor and a transverse flux counterpart with SMC core have been designed and will be constructed at UTS workshop. The motor size and core geometry were to a large extent determined by the dimensions of the SOMALOY ${ }^{\mathrm{TM}} 500$ preforms supplied by Höganäs AB, Sweden.

The claw pole motor is of the outer rotor structure. Fig. 1 illustrates the magnetically relevant parts of the rotor and the stator for one phase stack. The rotor consists of a mild steel case, three arrays of NdFeB magnets, and two aluminum end plates. The stator has three stacks and each consists of two pieces of magnetic composite claw pole discs. The stator teeth (claw poles) of three stacks are shifted by two-thirds of a
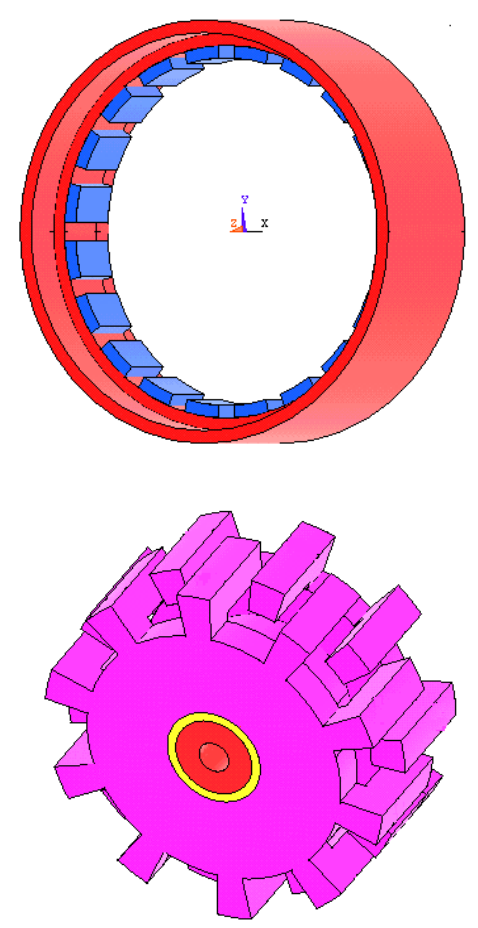

Figure 1. Magnetically relevant parts of one stack of claw pole motor

tooth-pitch or 120 electrical degrees. In contrast, the magnets with the same polarity of three arrays line up respectively. A pole number of 20 was chosen giving an operating frequency of $300 \mathrm{~Hz}$ at $1800 \mathrm{rpm}$. It is not an unrealistically high frequency to work at for the soft magnetic composite materials.

The stator winding is housed between two claw pole discs. Each phase stator winding is a single concentrated coil and the manufacturing cost is low because of the simple winding structure. This also allows a considerably higher fill factor to be achieved.

The composite soft magnetic material behaves the same in all directions and this isotropic magnetic property is far more important in designing hybrid flux machines, such as claw pole and transverse flux motors. Because of the complex geometry, the magnetic field in a claw pole motor is truly three dimensional at every point. In 3D flux machines, the armature carries significant field in all three directions. This is only achievable using the soft magnetic composite material. Consequently, for the correct calculation of magnetic field and motor characteristics, a 3D numerical method is required. A commercial finite element package, ANSYS, has been used for this purpose. Table 1 lists the dimensions and the major parameters of the claw pole design.

The claw pole structure is difficult to manufacture using electrical steels. The manufacturing process can be simplified by using injection molding technique and hence the 
Table I: Dimensions and major parameters of the prototype claw pole permanent magnet motor

\begin{tabular}{lc}
\hline \multicolumn{1}{c}{ Dimensions and parameters } & Quantities \\
\hline Rated frequency (Hz) & 300 \\
Number of phases & 3 \\
Rated voltage (V) & 50 \\
Rated power (W) & 560 \\
Rated current (A) & 5.2 \\
Rated speed (rev/min) & 1800 \\
Rated torque (Nm) & 1.8 \\
Maximum torque (Nm) & 2.4 \\
Rated power factor & 0.735 \\
Rated efficiency (\%) & 76 \\
Number of poles & 20 \\
Permanent magnet & NdFeB \\
Number of magnets & 60 \\
Stator core material & SOMOY \\
Number of turns of stator winding & 68 \\
Rotor outer radius (mm) & 50 \\
Rotor inner radius (mm) & 41 \\
Stator outer radius (mm) & 40 \\
Stator axial length of one stack (mm) & 36 \\
Shaft radius (mm) & 8 \\
Main airgap length (mm) & 1 \\
First sub-airgap length ${ }^{1}$ (mm) & 4.25 \\
Second sub-airgap length ${ }^{2}$ (mm) & 3 \\
\hline Note: &
\end{tabular}

Note:

1. The first sub-airgap is defined as the gap between the sides of the claw poles of the two separated pieces.

2. The second sub-airgap is defined as the gap between the top and the bottom surfaces of the claw poles of the two separated pieces.

manufacturing cost can be reduced. The complex structure of the stator iron core with up to 20 claw poles can be formed in a die and there is no further mechanical processing required, with of course no burring problems and the associated increased losses due to the surface currents.

The maximum relative permeability of SOMALOY ${ }^{\mathrm{TM}} 500$ is 500 , which is not high. This can be a particular problem for some small machines, such as induction and reluctance motors because they are magnetized from the armature and the magnetization current is relatively large. It is far less a problem for permanent magnet machines, whose magnetic circuit is basically determined by the large effective air gaps presented by the magnets. It is clear that this effect must be minimized in the design if the disadvantaged factor becomes important. In this design, it is solved at the expense of the use of lower no-load flux densities and larger core volumes.

\section{B. 3D Numerical Field Analysis}

Correct calculation of magnetic field and motor characteristics requires a $3 \mathrm{D}$ numerical method. The commercial finite element package ANSYS has been used for this purpose, allowing non-linear material properties and structural details to be considered. In the design of the prototype, the dimensions and parameters of the motor were first approximately determined by magnetic circuit analysis and then refined by the finite element analysis.

Since the claw pole machine has 3D magnetic fluxes, it is necessary to use 3D finite element analysis for an accurate determination of its parameters and performances. By taking the advantage of the periodical symmetry, only one pole pitch of the machine, as shown in Fig. 2, needs to be studied.

At the two radial boundary planes, the magnetic scalar potential used to solve the magnetic field distribution obeys the so-called half-periodical boundary conditions:

$$
\varphi_{m}(r, \Delta \theta / 2, z)=-\varphi_{m}(r,-\Delta \theta / 2,-z)
$$

where $\Delta \theta=18^{\circ}$ is the angle of one pole pitch. The original point of the cylindrical coordinate is located at the center of the stack. The conditions of the magnetic flux density are given in (2) and (3).

$$
\begin{gathered}
B_{r, \theta}(r, \Delta \theta / 2, z)=-B_{r, \theta}(r,-\Delta \theta / 2,-z) \\
B_{z}(r, \Delta \theta / 2, z)=B_{z}(r,-\Delta \theta / 2,-z)
\end{gathered}
$$

1) Magnetic field distribution at no-load: Fig. 3 shows the no-load magnetic distribution for when the main magnetic circuit has the highest permeability and the stator winding links the maximum magnetic flux. The lengths of the flux density vectors are proportional to the magnitudes.

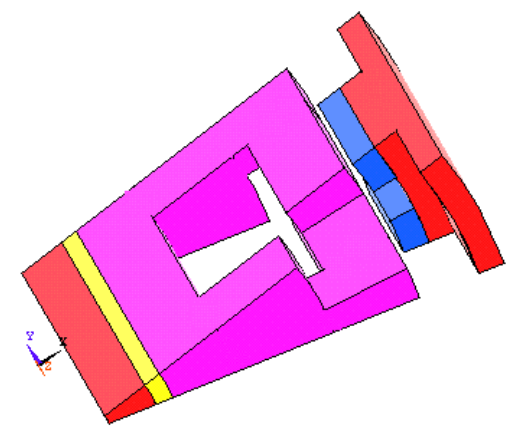

Figure 2. Region for field solution
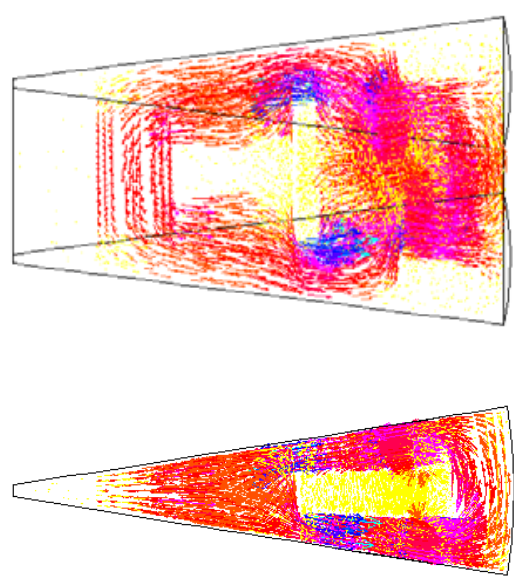

Figure 3. Vector plot of no-load flux density 
As expected, the major path for the magnetic flux of the permanent magnets is along one of the permanent magnets the main air gap - one of the composite claw pole stator core disks - the stator yoke - another composite claw pole stator core disk - main airgap - another permanent magnet and then - the mild steel rotor yoke to form a closed loop. There is also a considerable amount of leakage flux through the gaps between the side and end surfaces of the claw poles of the two separated pieces, defined as the first and second sub-air-gaps respectively. This is unwanted though inevitable. The first and second sub-air-gap lengths can be further increased to reduce the leakage flux. If too much material is taken away, however, this would harm the mechanical strength of the claw poles since the magnetic composite is brittle.

2) Magnetic flux linking the stator winding at no-load: As the rotor rotates, the flux linking the stator winding varies and an electromotive force $(e m f)$ is induced. The emf frequency depends on the rotor speed, while the emf waveform is determined by the waveform of the flux. At no load, the flux waveform was calculated by rotating the rotor magnets for one pole pitch in 20 steps. As plotted in Fig. 4, this flux waveform is almost perfectly sinusoidal versus the rotor position.

3) Cogging torque: Cogging torque is caused by the tendency of the rotor magnets to line up with the stator poles in a particular direction where the magnetic circuit has the highest permeance when the motor is under no-load. It can be calculated by the partial derivative of magnetic co-energy with respect to the angular displacement as

$$
T_{\operatorname{cog}}=\frac{\partial W_{f}^{\prime}}{\partial \theta}
$$

where $W_{f}^{\prime}$ is the total co-energy of the field and $\theta$ the rotor position. Numerically, this partial derivative can be calculated approximately as the variation of co-energy against the rotor angular displacement:

$$
T_{\operatorname{cog}} \approx \frac{\Delta W_{f}^{\prime}}{\Delta \theta}=\frac{W_{f 2}{ }^{\prime}-W_{f 1}{ }^{\prime}}{\theta_{2}-\theta_{1}}
$$

In general, this conventional virtual work method is accurate since the co-energy or energy of the whole model is considered. When the torque is small or a small displacement step is chosen, however, the values of the energy or co-energy are very close and the errors of field and energy or co-energy computations may affect the accuracy significantly. Conversely, if the displacement is too large, the calculated torque will fall into the average value over the region.

The Coulomb virtual work (CVW) method is applied in this computation, which calculates the global force acting on a moving structure by a direct, closed form differentiation of the magnetic energy or co-energy in the air gap between the movable and the fixed parts of the system under consideration [7]. The difficulty of choosing displacement is avoided. Fig. 5 shows the cogging torque variation versus the rotor position.

The harmonics of the cogging torque of one stack were computed by the Discrete Fourier Transformation (DFT) method to be

$$
\begin{array}{r}
T_{A} \approx 0.718 \sin 2 \theta+0.193 \sin 4 \theta-0.078 \sin 6 \theta \\
-0.080 \sin 8 \theta+0.017 \sin 10 \theta+0.025 \sin 12 \theta
\end{array}
$$

In equation (6), $\theta$ is the rotor angle in electrical degrees. Since the stator claw poles on the three stacks are shifted by 120 electrical degrees, the fundamental components and harmonics with orders 2, 4, 8, 10, etc. are cancelled each other. Only the harmonics with order 6 or its multiples remain. The magnitudes of the $6^{\text {th }}$ and $12^{\text {th }}$ harmonics of cogging torque are $0.234 \mathrm{Nm}$ and $0.070 \mathrm{Nm}$, respectively. These values are quite small compared with the rated torque of $1.8 \mathrm{Nm}$ and hence do not have a detrimental effect on the motor operation. For single-stack motors, however, the claw pole shape should be optimized to minimize the cogging toque, usually by using an irregular shape with tapered width and height along the pole.

In this design, the claw poles employ regular shapes for easy

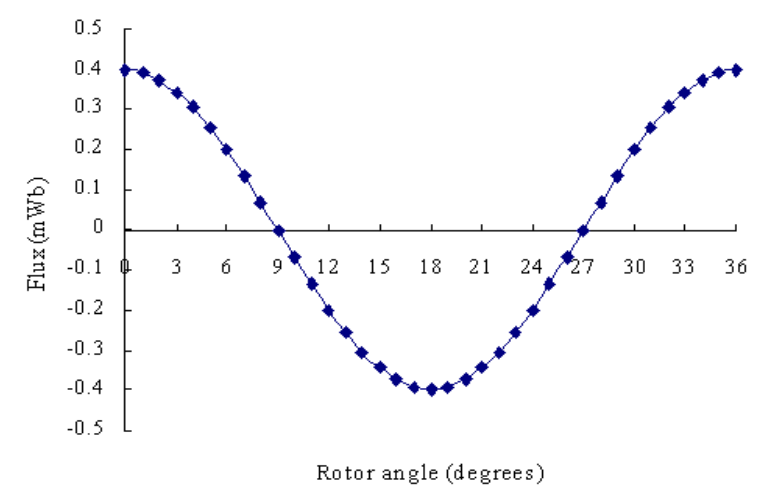

Figure 4. No-load flux linking the stator winding

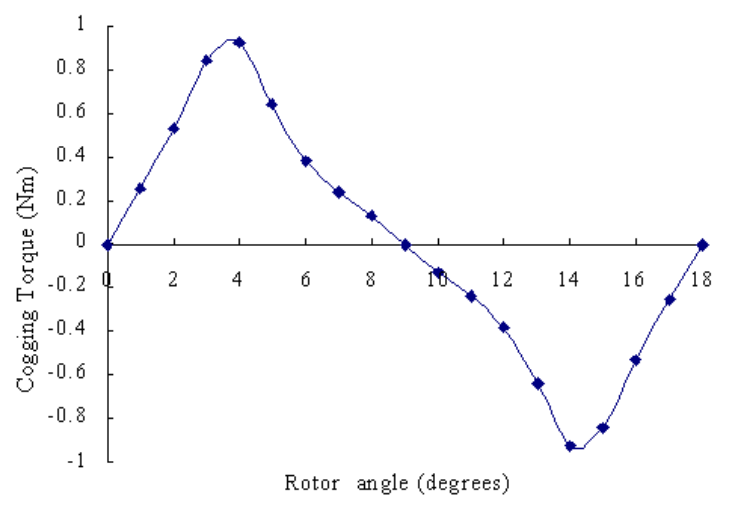

Figure 5. Cogging torque versus rotor angle 
prototype fabrication. Although the injection molding technique could be used for batch production, it is necessary to manufacture the prototypes by cold machining at the laboratory stage. The SMC material is brittle and special attention should be paid to its mechanical strength during machining, assembly and operation.

4) Reactance calculation: The synchronous reactance of the stator winding can be calculated by

$$
X_{1}=2 \pi f_{1} L_{1}
$$

where $L_{1}$ is the synchronous inductance of the stator winding in Henry. In the case of a three-stack motor, it equals the selfinductance of the stator winding, and can be calculated by

$$
L_{1}=\frac{N_{1} \phi_{1}}{I_{1}}
$$

where $\phi_{1}$ is the magnitude of the flux linking the stator winding due to a stator current $I_{1}$, and can be obtained from the results of the field analysis with stator current $I_{1}$ and the permanent magnets "switched off".

5) Magnetic field under load: The magnetic field distribution is also calculated with different load currents. The maximum stator magnetomotive force $(\mathrm{mm} f)$ at which the permanent magnets are possibly demagnetized can be determined by magnetic field analysis under load. In this prototype, it was found that the demagnetization $m m f$ is about 11,938 ampere-turns, far higher than the rated stator mmf. Therefore, the stator current is limited by the operation temperature rise of the winding, rather than the magnet demagnetization.

6) Core loss calculation: In rotary electrical machines, the magnetic field rotates. The core loss is caused not only by alternating but also by rotational magnetic fields, and should be properly considered properly in the design [8]. The $\mathbf{B}-\mathbf{H}$ relationship and core loss curves of SMC material SOMALOY ${ }^{\mathrm{TM}} 500$ used for the stator core were measured under 2D rotating excitation [4,5]. The quasi-3D properties were also obtained by the $2 \mathrm{D}$ tests and applied in the design calculation. In claw pole machines, the armature carries significant fluxes in all directions.

Like alternating core loss, the rotational core loss $P_{r}$ in $\mathrm{W} / \mathrm{kg}$ could be separated into three components: rotational hysteresis loss $P_{h}$, rotational eddy current loss $P_{e}$, and rotational anomalous loss $P_{a}$ as following

$$
P_{r}=P_{h}+P_{e}+P_{a}=P_{h}+C_{e}\left(f B_{P}\right)^{2}+C_{a}\left(f B_{P}\right)^{1.5}
$$

where $C_{e}$ and $C_{a}$ are constants depending on the material characteristics, $f$ the excitation frequency, and $B_{p}$ the peak flux density [9]. The hysteresis loss $P_{h}$ with alternating field approximately obeys the Steinmetz law

$$
P_{h}=C_{h} f B_{P}{ }^{n}
$$

However, the experimental study showed that the rotational core behaves very differently from the alternating counterpart. According to the similarity between the curve of rotational hysteresis loss against flux density $\mathrm{B}$ or Magnetization $\mathrm{M}$ and the torque/slip curve of a single-phase induction motor, a novel model was proposed [10]. The specific rotational hysteresis loss per cycle in an electrical steel sheet can be written in terms of four parameters, $a_{1}$ (in $\mathrm{J} / \mathrm{kg}$ ), $a_{2}$ (nondimensional), $a_{3}$ (non-dimensional), $M_{s}$ (saturation magnetization in $\mathrm{T}$ ), by

$$
\frac{P_{h r}}{f}=a_{1}\left[\frac{1 / s}{\left(a_{2}+1 / s\right)^{2}+a_{3}^{2}}-\frac{1 /(2-s)}{\left[a_{2}+1 /(2-s)\right]^{2}+a_{3}^{2}}\right]
$$

where $s=1-\frac{M}{M_{s}} \sqrt{1-\frac{1}{a_{2}^{2}+a_{3}^{2}}}$ and $\quad M=B / \mu_{0}-H$

The coefficients in the above models are determined by the experiment on material samples. The core losses in $\mathrm{W} / \mathrm{kg}$ of the samples are measured with different magnitudes of flux density and different frequencies under rotational excitation. Curve fitting technique by the least square is used for the coefficient determination. With the numerical field analysis, the core loss calculation can be done in each element.

\section{Performance Calculation}

The performance of the claw pole motor can be predicted by the equivalent circuit model as shown in Fig. 6, where $E_{1}$ is the induced stator emf due to the permanent magnets, $R_{1}$ the stator winding resistance, and $X_{1}$ the synchronous reactance.

The motor uses the standard six-transistor bridge drive circuit. It can operate in normal synchronous mode with open-loop control. With a closed-loop control of position feedback the motor can also operate in brushless DC mode where $I_{1}$ and $E_{1}$ are adjusted in phase for a maximum electromagnetic power at a given speed.

From the equivalent circuit shown in Fig. 6, the electromagnetic power and torque versus the load angle in a normal synchronous mode can be derived as

$$
\begin{aligned}
P_{e m}=m E_{1} I_{1} \cos \phi_{E I} & =\frac{m E_{1}\left[V_{1}\left(R_{1} \cos \delta+X_{1} \sin \delta\right)-R_{1} E_{1}\right]}{R_{1}^{2}+X_{1}^{2}}
\end{aligned}
$$




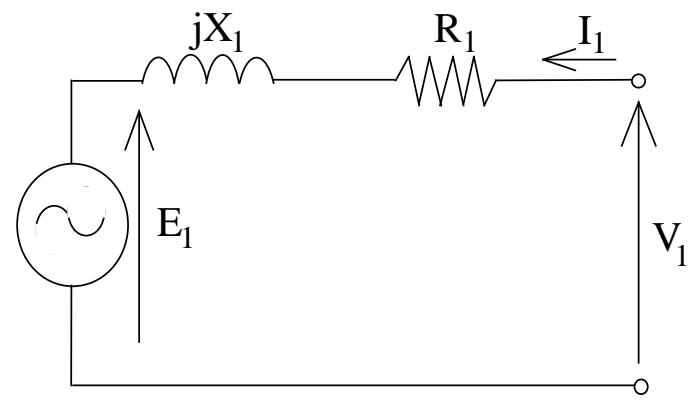

Figure 6. Equivalent circuit model of synchronous motors

$$
T=P_{e m} / \omega_{r}
$$

where $m$ is the number of phases of the stator windings, $\phi_{E I}$ the phase angle between $E_{1}$ and $I_{1}, \omega_{r}$ the rotor angular speed in mechanical radians per second, and $\delta$ the load angle. Fig. 7 plots the electromagnetic power against the load angle. When $\delta=90^{\circ}$ electrical, the electromagnetic power of the motor reaches a maximum of $716 \mathrm{~W}$, and the corresponding electromagnetic torque is $2.38 \mathrm{Nm}$.

The output power can be calculated by

$$
P_{\text {out }}=P_{\text {em }}-P_{\text {core }}-P_{\text {mec }}
$$

$P_{\text {mec }}$ is the mechanical loss and $P_{\text {core }}$ the core loss calculated by adding up the power dissipated in each element of stator core.

\section{TRANSVERSE FLUX MACHINE}

\section{A. Structure and Dimensions}

Permanent magnet machines with transverse flux structure are attracting increasing attention. In 1988, Weh proposed two versions of transverse flux machines (TFM) featuring high power density and high efficiency [11]. Motors of this type could produce very high values of torque or force at low speed and could find wide application in direct drives.

This paper proposes the design of a three phase three stack PM transverse flux motor with SMC core. The main sizes, i.e. the stator outer diameter and axial length are basically the same as that of the claw pole prototype. Fig. 8 illustrates the magnetically relevant parts of one stack. The motor also has an outer-rotor structure and each stack consists of two PM arrays mounted on SMC back plates. Table II lists the dimensions and major parameters of the TFM prototype.

\section{B. 3D Numerical Field Analysis}

Obviously, the complexity of the magnetic flux path makes a 3D finite element analysis a necessity.

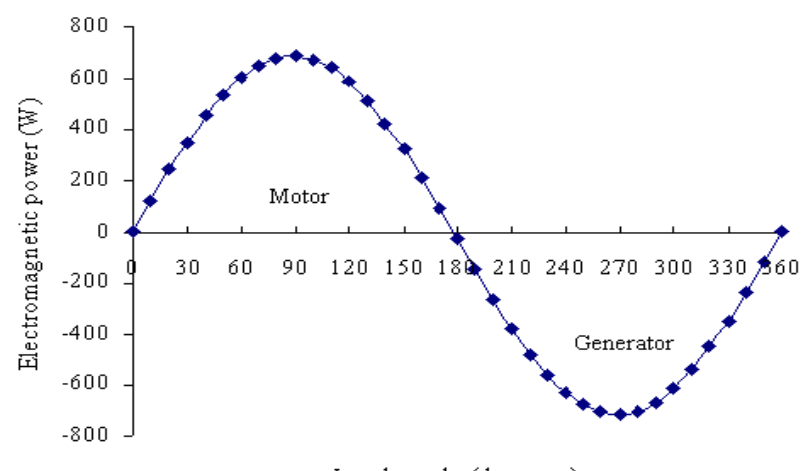

Load angle (degrees)

Figure 7. Electromagnetic power versus load angle of claw pole motor

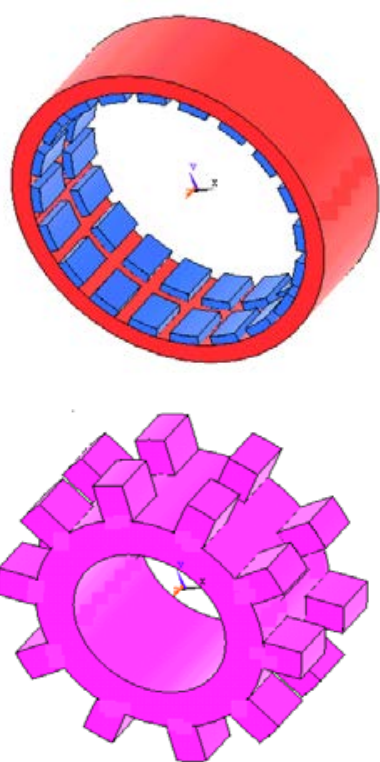

Figure 8. Magnetically relevant parts of one stack of TFM

Table II: Dimensions and major parameters of the permanent magnet transverse flux motor

\begin{tabular}{lc}
\hline \multicolumn{1}{c}{ Dimensions and parameters } & Quantities \\
\hline Rated frequency (Hz) & 300 \\
Number of phases & 3 \\
Rated voltage (V) & 50 \\
Rated power (W) & 1350 \\
Rated current (A) & 12.5 \\
Rated speed (rev/min) & 1800 \\
Rated torque (Nm) & 4.5 \\
Maximum torque (Nm) & 6.4 \\
Rated power factor & 0.774 \\
Rated efficiency (\%) & 78 \\
Number of poles & 20 \\
Permanent magnet & NdFeB \\
Number of magnets & 120 \\
Stator core material & SOMALY \\
Number of turns of stator winding & 54 \\
Rotor outer radius (mm) & 50 \\
Rotor inner radius (mm) & 41 \\
Stator outer radius (mm) & 40 \\
Stator axial length of one stack (mm) & 36 \\
Main airgap length (mm) & 1 \\
\hline
\end{tabular}


Because of the structure symmetry and periodical repetition, only one pole-pair region is required for magnetic field analysis. At the two radial boundary planes, the magnetic scalar potential used to solve the magnetic field distribution should follow the full periodical boundary conditions:

$$
\varphi_{m}(r, \Delta \theta, z)=\varphi_{m}(r,-\Delta \theta, z)
$$

where $\Delta \theta=18^{\circ}$ is the angle of one pole pitch. The original point of the cylindrical coordinate is located at the center of the stack.

No-load magnetic field distribution is calculated to find out the magnetic flux linking the stator winding and further the induced emf due to the rotation of the permanent magnets on the rotor. The motor structure should be adjusted such that the flux linkage of the stator winding is the maximum. Fig. 9 shows the no-load flux density vector distribution at maximum linked flux. The upper graph shows the main flux path in the plane perpendicular to the motion direction. The lower graph shows the field distribution in the parallel plane and it can be seen that quite large leakage flux exists between adjacent magnets.

The equivalent electric circuit for claw pole motors can also be used for predicting the TFM steady state performance. The induced emf in the stator winding due to the permanent magnets and the stator winding reactance can be determined from the results of 3D magnetic field analysis. Fig. 10 shows the relationship of the electromagnetic power and load angle when the machine operates in a normal open-loop synchronous mode. When $\delta=90^{\circ}$ electrical, the electromagnetic power of the motor reaches the maximum which equals $1967 \mathrm{~W}$, and the corresponding electromagnetic torque is $6.35 \mathrm{Nm}$.

\section{EXPERIMENTATION VALIDATION}

The above method of three dimensional field analysis, equivalent circuit parameter calculation, and performance prediction were validated by the experimental results of a single-phase SMC claw-pole motor prototype [9]. Fig. 11 and Fig. 12 plot together the measured and predicted cogging torque and induced emf in the state winding respectively. The theoretical and experimental results are in substantial agreement. The measured and calculated stator winding resistances and reactances, core losses, and torques with different stator current also match very well.

\section{COMPARISON AND CONCLUSIONS}

To investigate the potential of soft magnetic composite materials in manufacturing of small motors with complex structures, a three-phase three stack permanent magnet claw pole motor with SMC core and its transverse flux motor
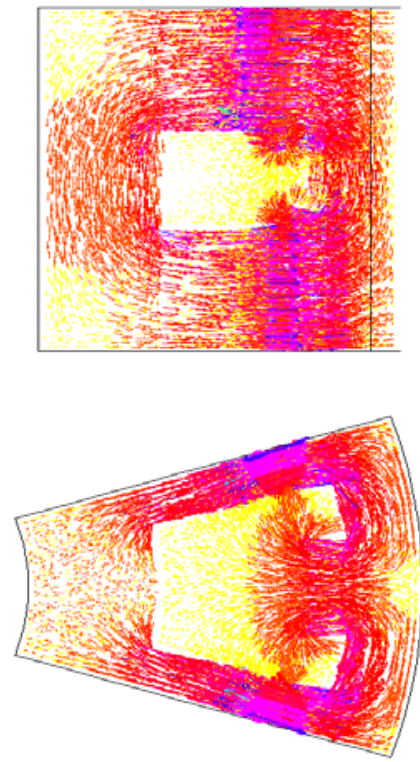

Figure 9. Magnetic flux density vectors at no-load

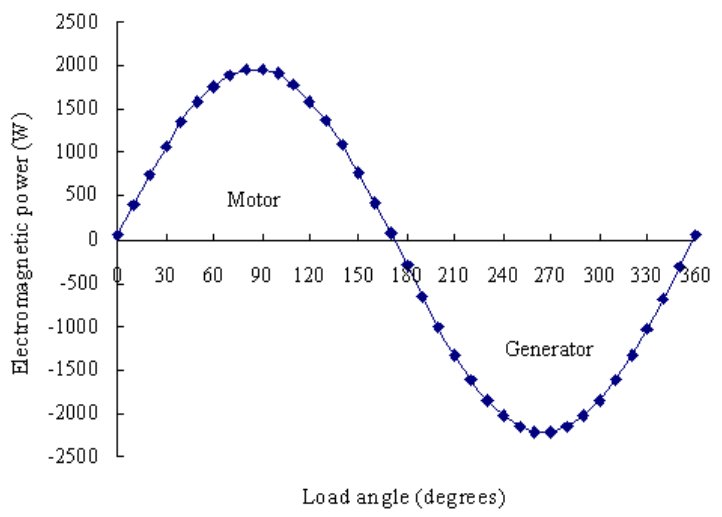

Figure 10. Electromagnetic power versus load angle of TFM prototype

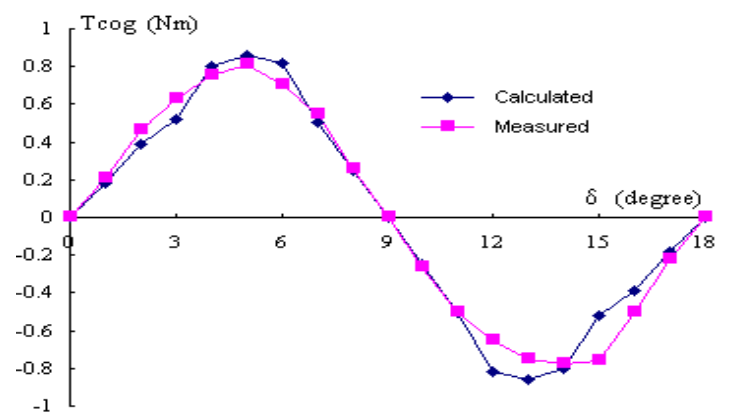

Figure 11. Comparison of calculated and measured cogging torque

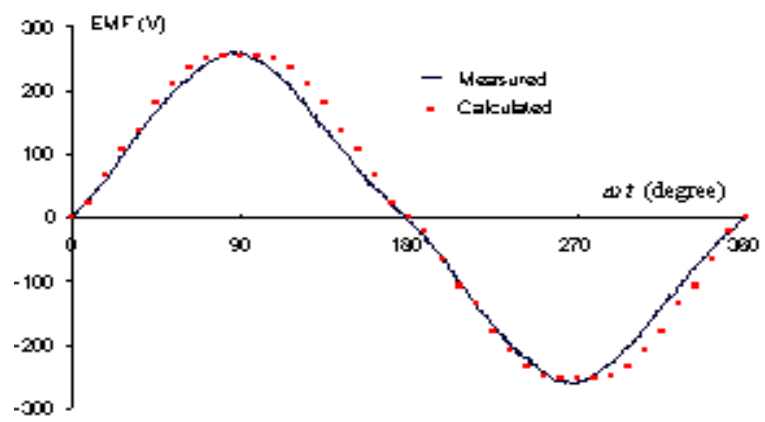

Figure 12. Measured and calculated stator emf waveforms at a rotor speed 
counterpart have been designed by 3D finite element analysis of magnetic fields using ANSYS. Claw pole armature machines are really a type of transverse flux motor (or vice versa) and the parameter calculation and performance prediction in the design of two prototypes can follow exactly the same procedure. The validated design method by a singlephase claw pole motor is also valid for transverse flux machines. Both prototypes have the same main sizes and hence effective iron cores. The transverse flux motor, however, uses twice as many permanent magnets and copper material and produces more than twice electromagnetic power at a given rotor speed.

Since SMC materials avoid the difficulties associated with lamination steels exposed to 3D alternating or rotating fields, they can be suitable for construction of all size motors with complex topologies, such as claw pole, transverse flux, and combined axial and radial flux motors. To fully take the advantages of SMC materials, the 3D flux machines are expected to operate at higher frequency where electrical steels have to surrender due to the large eddy current loss.

The motor prototypes are being constructed at UTS workshop by cold machining. However, the injection molding technique could be used for commercial production. It is expected that the motor performance would be comparable to or better than that of similar motors with electrical steel cores.

\section{ACKNOWLEDGMENT}

The authors would like to thank Höganäs AB, Sweden, for supplying preforms of SOMALOY ${ }^{\mathrm{TM}} 500$.

\section{REFERENCES}

[1] "The latest development in soft magnetic composite technology, from Högnäs Metal Powders”, Reports of Högnäs AB, Sweden, 1997-2001.

[2] A.G. Jack, "Experiences with the use of soft magnetic composites in electrical machines", Proceeding of International Conference on Electrical Machines, pp. 1441-1448, Istanbul, Turkey, September 1998,

[3] T.J. Hammons, H.B. Ertan, J.A. Tegopoulos, W. Drury, M. Ehsani, T. Nakata, A.G. Jack, “1998 ICEM review”, IEEE Power Engineering Review, pp. 12-17, February 1999

[4] J.J. Zhong, J.G. Zhu, V.S. Ramsden, and Y.G. Guo, "Magnetic properties of composite soft magnetic materials with 2-D fluxes”, Proceeding of Australasian Universities Power Engineering Conference, pp. 377-382, Hobart, Tasmania, Australia, September 27-30, 1998

[5] J.G. Zhu, J.J. Zhong, V.S. Ramsden, and Y.G. Guo, "Power losses of composite soft magnetic materials under two dimensional excitations", Journal of Applied Physics, vol. 85, pp. 4403-4405, April 1999

[6] A.G. Jack, B.C. Mecrow, C.P. Maddison, and N.A Wahab, "Claw pole armature permanent magnet machines exploiting soft iron powder metallurgy", Electric Machines and Drives Conference Record, IEEE International, MA1/5.1-5.3, 1997

[7] J.L. Coulomb and G. Meunier, "Finite element implementation of virtual work principle for magnetic or electrical force and torque computation", IEEE Trans. on Magnetics, vol. 20, pp. 1894-1896, September 1984

[8] J.G. Zhu and V.S. Ramsden, "Improved formulations for rotating core losses in rotating electrical machines”, IEEE Transactions on Magnetics, vol. 34, pp. 2234-2242, 1998

[9] F. Fiorillo and A. Novikov, "An improved approach to power losses in magnetic laminations under nonsinusoidal induction waveform”, IEEE Transactions on Magnetics, vol. 26, pp. 2904-2910, 1990

[10] Y.G. Guo, J.G. Zhu, and V.S. Ramsden, "Performance analysis and experimental validation of a single phase claw pole permanent magnet motor with composite magnetic core", Proceeding of the Third Chinese International Conference on Electrical Machines, pp. 179-182, Xi'an China, August 29-31, 1999

[11] H. Weh, H. Hoffmann, and J. Landrath, "New permanent magnet excited synchronous machine with high efficiency at low speed”, Proceeding of International Conference on Electrical Machines, pp. 35-40, 1988 